\title{
Long-stay medical-surgical intensive care unit patients in South Africa: Quality of life and mortality 1 year after discharge
}

\author{
E van der Merwe, ${ }^{1} \mathrm{MB}$ ChB, MMed (Int Med) (D); D Baker, ${ }^{1} \mathrm{MB}$ ChB; G Sharp, ${ }^{2}$ BSc, PhD; M van Niekerk, ${ }^{1} \mathrm{MB}$ ChB; F Paruk, ${ }^{3} \mathrm{MB} \mathrm{ChB}, \mathrm{MD}$ \\ ${ }^{1}$ Adult Critical Care Unit, Livingstone Tertiary Hospital, Gqeberha, South Africa; Faculty of Health Sciences, Walter Sisulu University, Mthatha, \\ South Africa \\ ${ }^{2}$ Department of Statistics, Faculty of Science, Nelson Mandela University, Gqeberha, South Africa \\ ${ }^{3}$ Department of Critical Care, Steve Biko Academic Hospital and Faculty of Health Sciences, University of Pretoria, South Africa
}

Corresponding author: E van der Merwe (lizvdm@gmail.com)

\begin{abstract}
Background. Although mortality is the primary measure of critical care outcome, the health-related quality of life (HRQOL) of survivors is often diminished. There is a paucity of South African research on HRQOL in intensive care unit (ICU) survivors.

Objectives. To evaluate the 1-year post-discharge data of long-stay ICU patients, a group known to consume 20 - $40 \%$ of ICU resources.

Methods. A 1-year prospective observational study was conducted in a multidisciplinary medical-surgical ICU. Adult patients who were mechanically ventilated beyond 6 days were included. Clinical and mortality data were collected. Pre-admission and 6- and 12-month HRQOL were measured with the Short Form-36 questionnaire. Physical and mental component summary scores (PCS and MCS) were calculated. Associations between 12-month mortality and poor HRQOL scores were determined.

Results. Of 119 patients enrolled, $40.3 \%$ had sustained trauma, 19.3\% were post-surgical and $40.3 \%$ had medical conditions; $29.2 \%$ were HIV-positive (HIV status was known for $74.8 \%$ of the cohort). The hospital and 12 -month mortality rates were $42.9 \%$ and $57.4 \%$ $(n=66 / 115)$, respectively. Age, longer ICU stay, higher disease severity scores and vasopressor use were associated with 12 -month mortality. The survivors' median PCS and MCS at 6 and 12 months were significantly lower compared with pre-admission scores (both $p<0.001)$. At 12 months, $53.1 \%$ of survivors demonstrated a poor PCS and $42.9 \%$ a poor MCS. Associations with poor 12-month PCS included longer ICU stay, male gender and trauma, while trauma and sepsis were associated with a poor 12-month MCS. Among the 19 trauma survivors, 78.9\% had a poor MCS and/or PCS. Of previously employed patients, $54.8 \%$ were unemployed at 12 months.

Conclusions. Patients ventilated beyond 6 days in a multidisciplinary ICU had a high mortality. Poor HRQOL at 12 months post discharge was frequently observed among survivors. Trauma was associated with poor 12-month outcomes. These findings highlight the need to further explore the outcomes of long-stay ICU patients in Africa.
\end{abstract}

S Afr Med J 2022;112(3):227-233. https://doi.org/10.7196/SAMJ.2022.v112i3.16191

Long-stay patients comprise $5-10 \%$ of the total intensive care unit (ICU) population, yet are reported to consume $20-40 \%$ of ICU bed days and other ICU resources. In recent years there has been a growing recognition globally that ICU outcomes should not be judged by mortality alone, but should include other outcome markers including the patient's total biopsychosocial wellbeing after hospital discharge. ${ }^{[1]}$

Reports from high-income countries (HICs) have demonstrated that the health-related quality of life (HRQOL) of many patients who survive critical illness is significantly diminished after the event. ${ }^{[2-4]}$ This decline may be attributed to physical impairment, neurocognitive dysfunction or psychological problems and is collectively referred to as the post intensive care syndrome (PICS). ${ }^{[5-7]}$ While patients with PICS have been shown to achieve an improvement in HRQOL during the first year after discharge, the HRQOL often remains lower than in the general population. ${ }^{[3,8]}$ These long-term effects of critical illness are even more prominent in ICU patients who are subjected to prolonged mechanical ventilation, many of whom develop chronic or persistent critical illness, a syndrome that develops in response to ongoing inflammation and multisystem impairment. ${ }^{[9]}$ Prolonged mechanical ventilation is considered in the context of patients who have tracheostomy placement or where the duration of mechanical ventilation exceeds 10 or 21 days, depending on the definition used. ${ }^{[10,11]}$ The causes for prolonged mechanical ventilation, which include respiratory, cardiac and neuromuscular disease, may well be related to critical illness other than the disease or injury that originally necessitated mechanical ventilation. ${ }^{[12]}$ Recent data also suggest that once a patient has been admitted to an ICU for $~ 7$ days, the original admission diagnosis and illness severity may no longer be reliable predictors of outcome and may indicate a transition to persistent critical illness. ${ }^{[13]}$ Days 7 - 10 on mechanical ventilation also coincide with the time when many ICUs would consider tracheostomy placement if a patient is still ventilator dependent. ${ }^{[14]}$

In resource-limited critical care settings, auditing outcomes is crucial for the fair allocation and prioritisation of resources. ${ }^{[15,16]}$ Furthermore, taking into account that HRQOL may be influenced by inadequate rehabilitation and psychosocial follow-up of long stayers, it would be important to evaluate quality of life after discharge in order to inform resource allocation for dedicated post-ICU clinics and rehabilitation services. ${ }^{[5]}$ Observations from well-resourced settings cannot be extrapolated to low- and middle-income countries such as South Africa (SA). To our knowledge, we do not have such data pertaining to long ICU stayers in SA. In SA, ICU admissions tend to be younger, HIV-positive rates are high, and there is a 
preponderance of surgical emergency and trauma admissions. ${ }^{[17-19]}$ These variations and the large proportion of the ICU budget that is spent on long-stay ICU survivors necessitate that we ascertain survival and the HRQOL in the SA setting.

\section{Objectives}

To determine mortality and HRQOL at 6 and 12 months after discharge of long-stay survivors in a tertiary ICU.

\section{Methods}

This prospective observational study was conducted in a closed multidisciplinary medical-surgical 16-bed tertiary ICU in Eastern Cape Province, SA. The ICU offers full-time on-site medical practitioner cover as well as specialist physician cover. There is a registered nurse-to-patient ratio of 3:4. Physiotherapy services are offered daily except on Sundays. The tertiary hospital serves $\sim 1.6$ million people residing in an area of $60000 \mathrm{~km}^{2}$. From 3 May 2017 to 2 May 2018, all patients aged $\geq 18$ years admitted to the ICU for the first time and who required mechanical ventilation for $\geq 7$ days were eligible for study inclusion. Patients for whom a preadmission (i.e. before the acute illness leading to admission) HRQOL questionnaire could not be completed, prisoners, and patients who were not fluent in isiXhosa, English or Afrikaans were excluded. Ethical clearance was obtained from the Walter Sisulu University Human Research Ethics Committee (ref. no. 120/2018). Written informed consent was obtained from patients or their surrogate decision-maker. In the situation of assent from a surrogate, the patient's consent was obtained when the patient was able to give it.

Data captured included demographics, comorbidities, employment status, clinical condition and treatment, as well as the occurrence of complications, sepsis or organ dysfunction during the course of the ICU stay. The Simplified Acute Physiology Score 3 (SAPS) and the maximum Sequential Organ Failure Assessment (SOFA) score were also noted on admission. Acute kidney injury was diagnosed according to the Kidney Diseases Improving Global Outcomes definition, ${ }^{[20]}$ and acute respiratory distress syndrome according to the Berlin classification. ${ }^{[21]}$ Sepsis and septic shock were defined according to the Sepsis-3 criteria. ${ }^{[22]}$

HRQOL was adjudged with the use of the Short Form-36 (SF-36) questionnaire, which was developed by the RAND Corporation as part of the Medical Outcomes Study. ${ }^{[23]}$ The SF-36 questionnaire comprises eight domains, namely physical functioning, role limitations due to physical health, bodily pain, general health perceptions, vitality, social functioning, role limitations due to emotional problems, and mental health. The physical and mental component summary scores (PCS and MCS, respectively) are calculated from these eight domains. Oblique rather than orthogonal scores were formed for the PCS and MCS. The oblique method as opposed to orthogonal scoring reduces the correlation between the components due to the inherent correlation between the items which are used to form the components. ${ }^{[24]}$ No population norms for the PCS and MCS are available for SA or any African countries. The original US norms for the mean (standard deviation (SD)) PCS and MCS were 50 (10), ${ }^{[25]}$ and a minimally important difference (MID) of at least 3 points is suggested for the SF-36. ${ }^{[26]}$ For the purposes of the present study, a poor HRQOL was defined as a combination of a decrease in the 12-month PCS or MCS of $\geq 3$ compared with the pre-admission score, as well as a score of $<47$ (a decrease of more than the MID below 50). These criteria were to ensure that the pooroutcome group was accurately characterised by excluding patients who despite a decrease still had a reasonable HRQOL, and also to take into account the effect of a pre-existing poor HRQOL. The retrospective pre-admission HRQOL was worked out with the patient and/or a family member. The SF-36 was repeated telephonically or in person at 6 and 12 months after hospital discharge, and employment status was also documented. The hospital, ICU, and 6- and 12-month mortality was recorded.

Data were captured in Excel 2016 (Microsoft Corp., USA) and analysed with RStudio, version 3.6.1, 2019 (RStudio, USA, http:// www.r-project.org) and Statistica version 13 (TIBCO Software Inc., USA). Continuous data were tested for normality using Pearson's $\chi^{2}$ test. Normally distributed data are reported as means (SD) and skewed data as medians (interquartile range (IQR)). Discrete data are presented as numbers (percentages). Group comparisons were done in relation to survival at 12 months. Patients with a poor HRQOL (PCS and MCS) at 12 months were compared with patients who had a good HRQOL outcome at 12 months. Student's $t$-test and the Mann-Whitney $U$-test were used to compare continuous data and the $\chi^{2}$ and Fisher's exact tests were used for discrete data, as appropriate. Variables with a bivariate analysis demonstrating a $10 \%$ level of significance (alpha level $\leq 0.1$ ) between groups were considered in the logistic regression models. A $p$-value $<0.05$ was set as the threshold of statistical significance.

\section{Results}

During the study period, 934 admissions were screened for potential inclusion, of whom 133 were mechanically ventilated for $\geq 7$ days. There were 14 exclusions, as there were 2 prisoners and 2 cases in which informed consent could not be obtained, and 10 patients were $<18$ years old. Of 119 patients enrolled, 49 were ultimately reviewed at the 12-month visit (Fig. 1). Four patients were lost to follow-up between 6 and 12 months.

The characteristics of the cohort are presented in Table 1. The main admission diagnoses were trauma $(n=48 ; 40.3 \%)$, communityacquired pneumonia $(n=16 ; 13.4 \%)$, complicated intra-abdominal sepsis $(n=8 ; 6.7 \%)$, pancreatitis $(n=6 ; 5 \%)$, self-harm $(n=4$; $3.4 \%)$, complicated soft-tissue infections $(n=4 ; 3.4 \%)$ and neuromuscular weakness $(n=5 ; 4.2 \%)$. The diagnoses of the 5 patients with neuromuscular weakness on admission were Guillain-Barré syndrome (3 cases), and a myasthenic crisis and severe hypokalaemia ( 1 case each). Among the trauma patients, 28 (23.5\% of the total of 119 patients) had been involved in motor vehicle accidents, $16(13.4 \%)$ were assault cases, $2(1.68 \%)$ had burn wounds and 1 presented following a fall. Eighty-nine patients $(74.8 \%)$ had known HIV status, of whom $29.2 \%$ were HIV-positive.

The ICU, hospital, and 6- and 12-month mortality rates for the cohort were $31.1 \%, 42.9 \%, 52.9 \%$ and $57.4 \%(n=66 / 115)$, respectively. The presence or development of sepsis was associated with a significant increase in hospital mortality ( $14.6 \%$ v. $45.1 \%$; $p=0.03)$. Patient characteristics, complications and therapy in relation to 12-month mortality are shown in Table 1 . Where numbers permitted, multiple logistic regression analysis was performed, and this confirmed these associations with comparable odds ratios. Age, longer ICU stay, higher SAPS and maximum SOFA scores as well as vasopressor use were found to be significantly associated with 12-month mortality. There were trends for male sex and sepsis (on admission or ICU acquired) to be associated with increased mortality.

Seventy-five percent of the pre-admission SF-36 questionnaires were completed by the patients themselves and the rest by a surrogate. On follow-up, they were completed by the patients. The median (IQR) pre-admission PCS was 58.5 (50.6 - 60.9). At 6 months it was significantly lower at $40.5(28.9-52.5)(p<0.001)$, and this lower median score persisted at 12 months at $42.6(31.2-51.3)(p=0.84,6 \mathrm{v}$. 12 months) (Fig. 2). The median pre-admission MCS was 55.5 (47.4 - 
60.7). At 6 months it was significantly lower at 44.0 (32.9 - 54.4) $(p<0.001)$, and this lower score also persisted at 12 months at 45.4 (35.8 - 54.8) ( $p=0.64,6$ v. 12 months) (Fig. 3). Similar to the 6-month

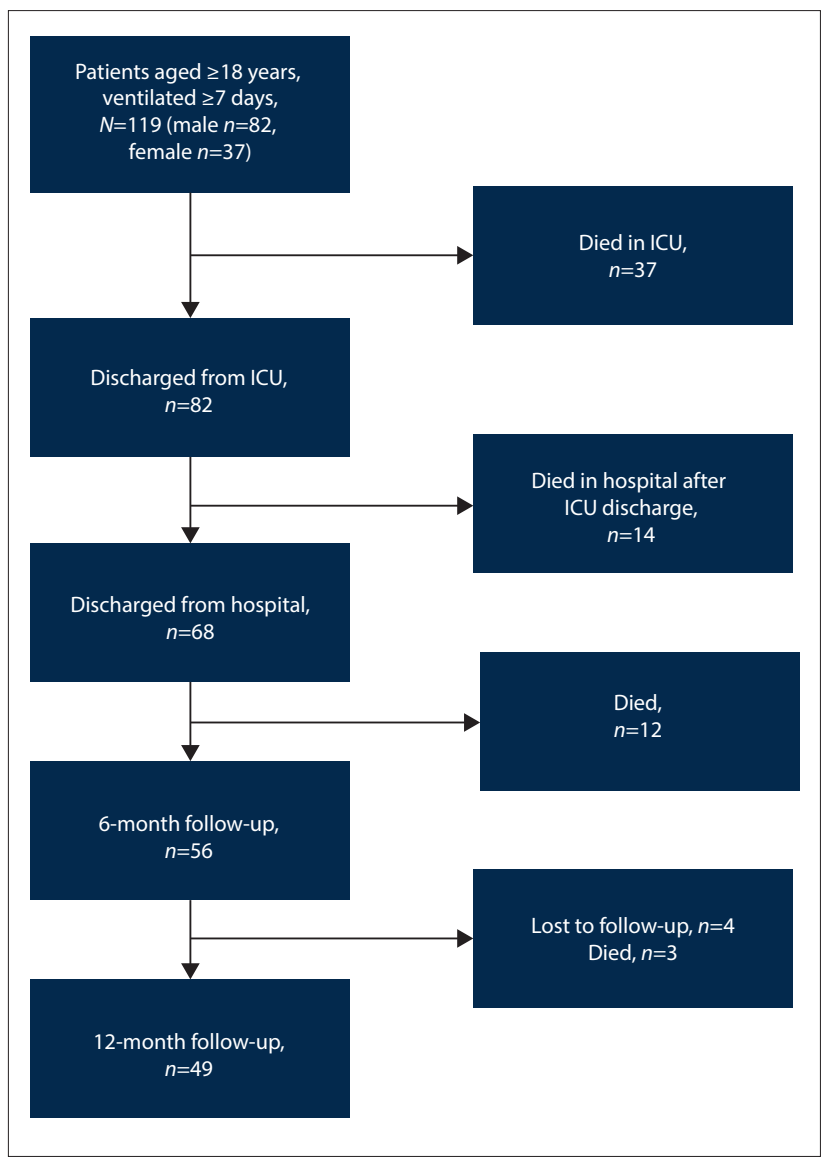

Fig. 1. Summary of outcome of study participants. (ICU = intensive care unit.) scores, the median 12-month PCS and MCS were significantly lower compared with the pre-admission scores ( $p<0.001$ for both).

At 12 months, 26 (53.1\%) of the survivors were observed to have a poor mean PCS, while 21 (42.9\%) demonstrated a poor mean MCS; $57.1 \%$ had a low PCS and/or a low MCS. The pre-admission PCS and MCS of patients with poor outcomes were comparable to the good-outcome group (Table 2). There was considerable overlap between patients with a poor PCS and MCS: 19 patients (38.8\% of the survivors) had low scores for both. While there was a significant decline in the poor-outcome group's score from pre-admission to 12 months, the good-outcome group's 6 - and 12-month scores were comparable to the pre-admission scores (Table 2).

A longer ICU stay (median (IQR) $23.5(15-36)$ days v. 15 (11 $22)$ days; $p=0.035)$, male sex $(69.2 \%$ v. $47.8 \% ; p=0.016)$ and trauma $(57.7 \%$ v. $17.4 \% ; p=0.007)$ were associated with a poor 12 -month

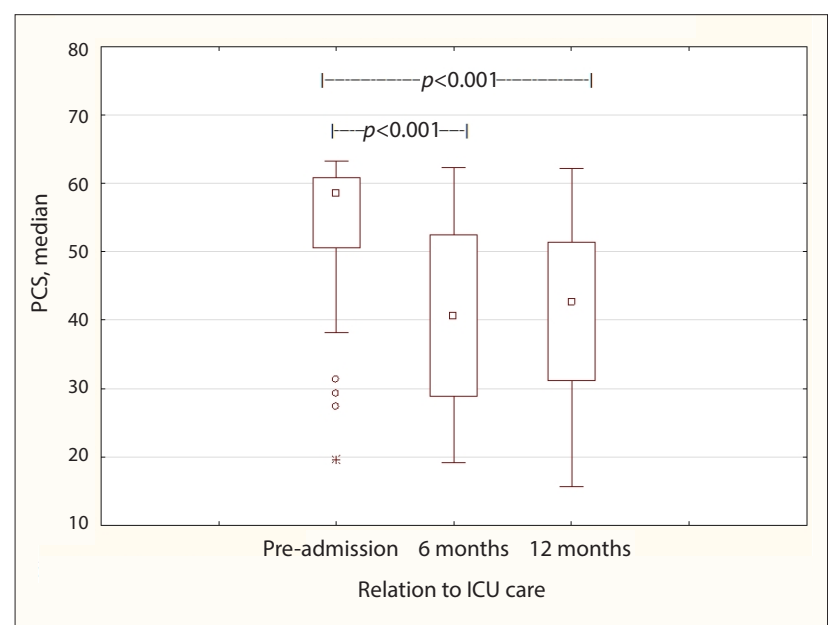

Fig. 2. Short Form-36 PCS: pre-admission and at 6 and 12 months after ICU care. Box: $25-75 \%$, whisker: non-outlier range. (PCS = physical component summary score; $I C U=$ intensive care unit.)

Table 1. Patient characteristics, therapy and complications in relation to 12-month survival

\begin{tabular}{|c|c|c|c|c|c|}
\hline & Cohort $(N=119)$ & $\begin{array}{l}12 \text {-month } \\
\text { survivors } \\
(N=49)\end{array}$ & $\begin{array}{l}\text { 12-month } \\
\text { non-survivors } \\
(N=66)\end{array}$ & $p$-value & $\begin{array}{l}\text { OR }(\mathrm{CI}) \text { (per } \\
\text { unit change } \\
\text { for continuous } \\
\text { variables) }\end{array}$ \\
\hline Age (years), median (IQR) & $37(27-53)$ & $32(24-47)$ & $41(31-55)$ & 0.01 & $1.04(1.01-1.07)$ \\
\hline Male gender, $n(\%)$ & $82(68.9)$ & $29(59.2)$ & $50(75.8)$ & 0.069 & $2.15(0.97-4.80)$ \\
\hline ICU days, median (IQR) & $16(10-23)$ & $17(13-28)$ & $13(9-21)$ & 0.015 & $0.96(0.93-0.99)$ \\
\hline SAPS, median (IQR) & $55(49-62)$ & $51(44-58)$ & $57(51-64)$ & 0.025 & $1.04(1.01-1.07)$ \\
\hline Maximum SOFA score, median (IQR) & $8.0(5.0-11.0)$ & $7.0(4-9)$ & $8.0(6-13)$ & 0.002 & $1.18(1.07-1.32)$ \\
\hline Days ventilated, median (IQR) & $12(8-19)$ & $14.0(9-20)$ & $10.0(8-19)$ & 0.167 & $0.98(0.95-1.01)$ \\
\hline ARDS, $n(\%)$ & $25(21.0)$ & $13(26.5)$ & $12(18.2)$ & 0.361 & $0.62(0.25-1.50)$ \\
\hline Vasopressor, $n(\%)$ & $61(51.3)$ & $18(36.7)$ & $41(62.1)$ & 0.009 & $2.82(1.32-6.07)$ \\
\hline AKI, $n(\%)$ & $91(76.4)$ & $34(69.4)$ & $53(80.3)$ & 0.194 & $1.80(0.76-4.24)$ \\
\hline Dialysed, $n(\%)$ & $29(24.4)$ & $10(20.4)$ & $18(27.3)$ & 0.51 & $1.46(0.61-3.53)$ \\
\hline Sepsis (community acquired or nosocomial), $n(\%)$ & $81(68.1)$ & $29(59.2)$ & $50(75.8)$ & 0.069 & $2.16(0.97-4.80)$ \\
\hline Comorbidity present, $n(\%)$ & $49(41.2)$ & $19(38.8)$ & $30(45.5)$ & 0.568 & - \\
\hline \multicolumn{6}{|l|}{ Referring discipline, $n(\%)$} \\
\hline Trauma & $48(40.3)$ & $19(38.8)$ & $27(40.9)$ & 0.886 & - \\
\hline Surgery & $23(19.3)$ & $9(18.4)$ & $14(21.2)$ & 0.870 & - \\
\hline Medicine & $48(40.3)$ & $21(42.9)$ & $25(37.8)$ & 0.725 & - \\
\hline Known HIV status $(n=89)$ positive, $n(\%)$ & $26(29.2)$ & $15(37.5)$ & $10(21.7)$ & 0.153 & - \\
\hline
\end{tabular}


Table 2. Comparison between the poor-outcome and good-outcome groups' Short Form-36 PCS and MCS scores

\begin{tabular}{lllll}
\hline Variable & Time frame & Poor-outcome group & Good-outcome group & $p$-value \\
\hline PCS, median (IQR) & $n$ & 26 & 23 & \\
& Pre-admission & $59.9(54.3-60.9)$ & $55.5(42.3-59.8)$ & 0.063 \\
& 6 months & $30.3(24.6-42.0)$ & $51.8(36.6-59.7)$ & $<0.001$ \\
& 12 months & $32(25.5-37.9)$ & $51.7(47.7-59.6)$ & $<0.001$ \\
& $p$-value (pre-admission v. 12 months) & $<0.001$ & 0.677 & \\
MCS, median (IQR) & $n$ & 21 & 28 & 0.0738 \\
& Pre-admission & $58.6(53.5-61.6)$ & $52.3(43.9-59.5)$ & 0.003 \\
& 6 months & $34.6(28.0-45.3)$ & $45.1(42.2-58.6)$ & $<0.001$ \\
& 12 months & $35.8(23.3-39.8)$ & $53.9(48.4-57.1)$ & \\
MCS = mental component summary score; PCS = physical component summary score; IQR = interquartile range. & & &
\end{tabular}

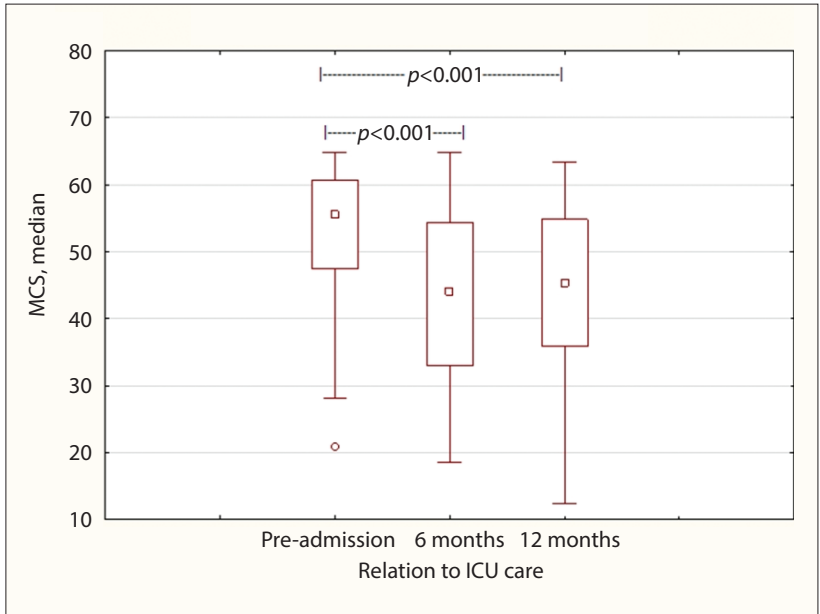

Fig. 3. Short Form-36 MCS: pre-admission and at 6 months and 12 months after ICU care. Box: 25 - 75\%, whisker: non-outlier range. (MCS = mental component summary score; ICU intensive care unit.)

PCS. Patients with a poor 12-month MCS were more likely to have had sepsis $(76.2 \%$ v. $46.2 \% ; p=0.036)$ and a diagnosis of trauma $(57 \%$ v. $28 \%$; $p=0.038$ ) compared with patients who demonstrated a good 12-month MCS. Among the 19 patients who had both a poor MCS and a poor PCS at 12 months, $12(63.2 \%)$ had been admitted with trauma. Furthermore, among the 19 trauma survivors, $78.9 \%$ had a poor HRQOL and $63.2 \%$ scored low for both the MCS and the PCS. A good 12-month PCS and MCS were both associated with a medical admission diagnosis as opposed to a surgical one $(65.2 \%$ v. $30 \%$; $p=0.004$ and $60.7 \%$ v. $19 \% ; p=0.38$, respectively). The domain scores of the poor 12-month PCS and MCS groups are shown in Fig. 4.

The unemployment rate (excluding pensioners and students) pre-admission was $40.0 \%$. Seventeen of the 31 survivors (54.8\%) who were employed pre-admission had not returned to any form of employment at 12 months.

\section{Discussion}

To the authors' knowledge, this is the first SA study to describe long-term outcomes of adult ICU patients ventilated beyond 6 days. Patients were found to have a high 12-month mortality, and the HRQOL of $57.1 \%$ of the survivors was significantly diminished from pre-admission. The median age of 37 years, the high percentage of trauma cases and the 29.2\% HIV-positive rate contrasts with longstay cohorts from HICs, where patients tend to be older and where there are far fewer trauma-related admissions. ${ }^{[8,27]}$
While the 1-year mortality rate of $57.4 \%$ is comparable to studies from high-income countries, it is nonetheless high taking into account the median age of this study population and that the oldest patient was 55 years old. ${ }^{[9,26,27]}$ In the past 15 years, reports from HICs have consistently shown that chronic critical illness with or without prolonged mechanical ventilation is associated with a high 1 -year mortality that varies from $48 \%$ to $68 \%{ }^{[9,28,29]}$ The ICU and hospital mortality of $31.1 \%$ and $42.9 \%$, respectively, in our long-stay cohort are also high taking into account that the overall 2017 ICU and hospital mortality in the same unit and hospital for all ICU admissions were $13.3 \%$ and $21.4 \%$, respectively. ${ }^{[17]}$ It is worth noting that $21.2 \%$ of the deaths occurred while in hospital post ICU discharge, and a further $18.2 \%$ occurred within 6 months after hospital discharge. This finding points towards the fact that long-stay patients warrant some form of monitoring after discharge from the ICU for setbacks, both in the hospital and on an outpatient basis.

This study demonstrated that 12-month mortality was associated with older age, higher SAPS and SOFA scores, and the need for vasopressor therapy. This is in keeping with previous findings of significant associations between mortality and increasing age, vasopressor use, thrombocytopenia, chronic kidney disease, acute kidney injury and renal replacement therapy in long-stay ICU patients. ${ }^{[1,30]}$ Interestingly, severity of disease on admission has not been consistently linked to mortality among patients with long-stay chronic critical illness. ${ }^{[9]}$ Findings from larger cohorts have shown that most severity scores and admission diagnoses lose their discrimination once ICU patients stay for longer than 7 - 10 days. ${ }^{[13,27,31]}$ This is probably because patients undergo diverse intercurrent events that become the determinants of mortality, rather than the initial diagnosis or the severity of illness on admission. ${ }^{[12]}$ As such, it is not surprising that the admission diagnoses in our cohort had no impact on 12-month survival. ICU-acquired sepsis contributes to self-perpetuating persistent inflammation, immunosuppression and catabolism syndrome in long-stay ICU patients. ${ }^{[31,32]}$ This may well explain why patients who were either admitted with infections or subsequently developed ICU-acquired infections demonstrated a trend towards an increase in 1-year mortality. The longer ICU stay of 12 -month survivors compared with non-survivors may be explained by the fact that $56.1 \%$ of deaths occurred during the ICU stay.

Among ICU survivors, the ability to live independently and return to work and a good HRQOL are important considerations. In the absence of population norms for the SF-36 in SA, the survivors' preadmission median (IQR) PCS of 58.5 (50.6 - 60.9) and MCS of 55.5 (47.4 - 60.7) were somewhat higher than the updated US population norms (mean (SD) PCS of 49.22 (15.13) and MCS of 53.78 (13.14)), 


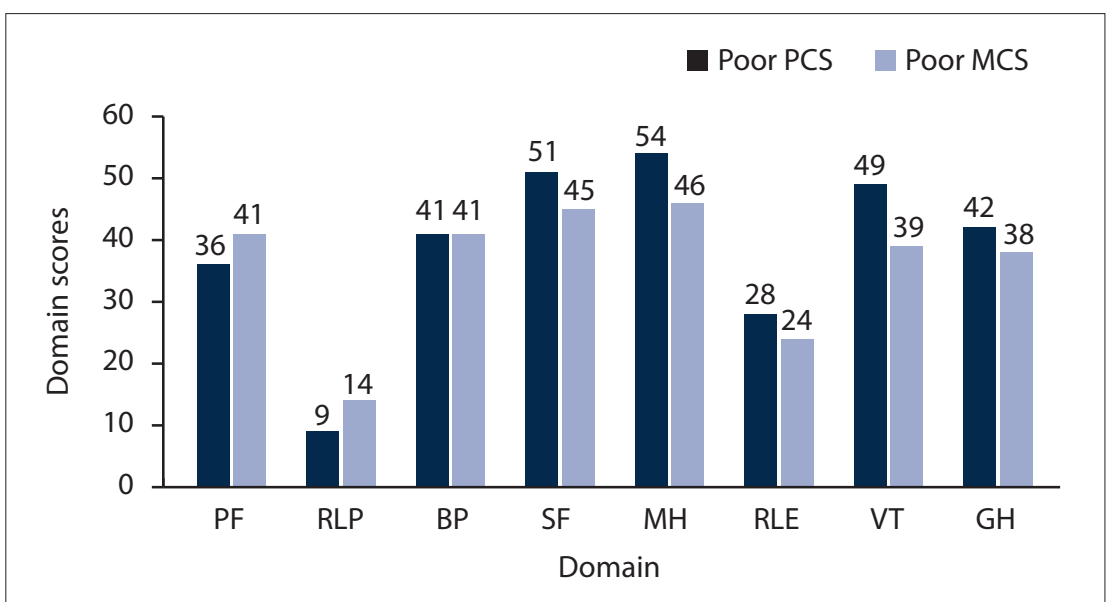

Fig. 4. Domain scores for the poor 12-month PCS and MCS groups. (PCS = physical component summary score; $M C S=$ mental component summary score; $P F=$ physical functioning; $R L P=$ role limitations due to physical health; $B P=$ bodily pain; $S F=$ social functioning; $M H=$ mental health; $R L E=$ role limitations due to emotional problems; $V T=$ vitality; $G H=$ general health perception.)

and were comparable to the control group of a study of young, largely male, trauma survivors in Johannesburg with a mean (SD) PCS of 57.6 (5.1) and MCS of 50.3 (10.3). ${ }^{[38]}$ This last finding reflects the similar mean age and sex of the enrolled patients in these two studies. At 6 months our study cohort demonstrated a significantly lower median MCS and PCS compared with their preadmission assessment, and this persisted even at 12 months. In alignment with previous findings, the PCS was more affected than the MCS. ${ }^{[8,29,34,35]}$ It has been suggested that this may signify an optimism obtained after seemingly 'cheating death'. ${ }^{[3]}$ Another possible explanation may be that different aspects of quality of life recover at variable rates, although reports have not been consistent regarding the order and rate of recovery of the components. ${ }^{[34,36]}$ A large meta-analysis concluded that although physical aspects improved slowly over the years, mental and emotional aspects remained stagnant or declined further over time. ${ }^{[37]}$

At 12 months, $53.1 \%$ of the cohort were found to have a poor PCS and $42.9 \%$ had a poor MCS. Furthermore, both of these pooroutcome subgroups' median component summary scores were significantly lower than their pre-admission scores. The group with a good 12-month HRQOL (for PCS and MCS) had achieved recovery within 6 months. There are no studies in SA pertaining to the long-term HRQOL outcomes of long-stay patients. A 1-year follow-up study conducted in Cape Town of 46 critically ill trauma patients (intubated for a mean of 3 days) found low mean HRQOL domain scores $(43-53 \%)$ at 12 months' follow-up. ${ }^{[35]}$ In Johannesburg, a 6-month follow-up study among 42 patients admitted to an ICU with penetrating chest injury found that the 6-month PCS and MCS were significantly reduced for those ventilated for $\geq 5$ days compared with their pre-admission HRQOL scores. ${ }^{[38]}$ Interestingly, the mean (SD) 6-month PCS (45 (8)) and MCS (53 (8)) in this study ${ }^{[38]}$ were somewhat higher than the corresponding 6-month values in our study. This may be explained by the differences in the case mix.

Previous studies have demonstrated that the ICU survivor's pre-admission HRQOL has a significant effect on HRQOL after critical illness, so pre-ICU admission HRQOL should also be measured in order to minimise bias. ${ }^{[39-41]}$ As expected, poor HRQOL pre-ICU also correlates with a poor outcome after ICU admission. ${ }^{[3,41,42]}$ In a large systematic review of the long-term HRQOL of ICU survivors, $<20 \%$ of studies reported pre-admission HRQOL, and this was considered a limitation in terms of interpreting outcomes. ${ }^{[2]}$ Although most patients cannot complete questionnaires themselves at the time of ICU admission, this can be overcome by either completing the questionnaire retrospectively when the patient is capacitated or seeking the assistance of proxies. Although recall bias may influence the results, this is not considered a reason for not measuring the pre-admission HRQOL. ${ }^{[43]}$ Surrogates tend to underestimate the HRQOL, but the difference is small, ${ }^{[44]}$ and the assistance of proxies to reliably assess the HRQOL of critically ill patients on admission has been

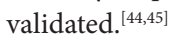

A poor 12-month PCS was found to be more common in patients with a longer ICU stay, male sex or a traumatic injury, and a poor 12-month MCS was associated with sepsis (on admission or ICU acquired) or traumatic injury. Logistic regression analysis for markers of poor 12-month MCS and PCS was not feasible owing to the small final dataset, but it is likely that the association with male sex may be explained by the number of trauma cases, as 17 of the 19 trauma cases were male. A large systematic review has also reported that trauma is a risk factor for a poor long-term HRQOL in ICU patients. ${ }^{[37]}$ This, and the fact that the majority of the survivors who had both a poor 12 -month MCS and PCS were trauma patients (12 of 19 patients), is in keeping with the previously recorded healthcare and social burden of trauma in SA. ${ }^{[46,47]}$

Although most of the domain scores of the patients with poor MCS and PCS scores were low, the domains that were most affected in both groups comprised role limitations due to physical health and emotional problems. These two domains are indicative of problems with work or other daily activities as a result of physical health and emotional problems, respectively. A previous SA study among trauma ICU survivors has described similar findings. ${ }^{[48]}$

The finding that $54.8 \%$ of previously employed ICU survivors were no longer employed at 12 months is a high figure and is in keeping with previous findings of postICU unemployment ranging from $32 \%$ to $48 \%$, albeit in older patient cohorts. ${ }^{[35,49-51]}$ This finding may relate to physical, mental and neurocognitive problems among longstay survivors and warrants further investigation. Extraneous economic forces may well contribute to employment status change; however, the SA unemployment rate has shown minimal changes during the study period of 2 years. ${ }^{[52]}$

\section{Study strengths and limitations}

The strength of this study lies in the inclusion of a pre-admission HRQL measurement as well as the small number of patients who were lost to long-term follow-up. The prospective enrolment, including the documentation of multiple contact numbers, as well as the fact that follow-up interviews were largely telephonic, may account for the low rate of attrition. This study also shows that despite challenges in SA such as informal housing and migrant labour, it is feasible to trace most patients telephonically 1 year after hospital discharge.

The small number of survivors at 12-month follow-up was a limiting factor, as it precluded logistic regression analysis 
for markers of a poor 12-month HRQOL outcome. An additional limitation is the absence of population norms for HRQOL for SA patients, although this was partially overcome by comparing the patients' scores with their own pre-admission scores. Both the use of proxies and recall bias may have influenced the retrospectively measured pre-admission HRQOL scores.

\section{Conclusions}

This study provides insights in terms of the expected outcomes for medical-surgical patients who require ventilation beyond 6 days in a country where ICU resources are restricted and the practice of triaging referrals is a reality. ${ }^{[53]}$ Our findings demonstrate that long-stay patients have a high mortality risk, and that there is a high prevalence of poor quality of life at 12 months among the survivors. Considering that it has previously been observed that both physicians and surrogates over-estimate the chances of survival in patients who require $7-10$ days of mechanical ventilation, these findings would provide useful additional information to clinicians who practise in a similar setting. ${ }^{[54]}$ The findings are important in terms of adjusting the expectations of patients, surrogates and attending physicians, not only regarding the probability of survival but also the expected road to recovery, and in establishing whether these align with a particular patient's goals and values. The finding that long-stay ICU survivors, and in particular the subset of trauma survivors, frequently had a poor long-term HRQOL makes a case for ensuring appropriate access to multidisciplinary rehabilitation and mental health services. Furthermore, there is a definite need to evaluate long-term outcomes among long-stay ICU patients in SA, as well as their access to rehabilitation and mental health services.

\section{Declaration. None.}

Acknowledgements. Stephan Venter for his contribution to the study's conception.

Author contributions. EvdM: study design, protocol, data collection, manuscript writing. DB: data collection, manuscript writing. GS: cleaned data, performed the statistical analysis and manuscript writing. MvN: data collection, manuscript writing. FP: manuscript writing.

Funding. South African Critical Care Society research grant.

Conflicts of interest. None.

1. Jackson JC, Gordon SM, Ely EW, Burger C, Hopkins RO. Research issues in the evaluation of cognitive impairment in intensive care unit survivors. Intensive Care Med 2004;30(11):2009-2016. https://doi. impairment in intensive care unt
org $/ 10.1007 / \mathrm{s} 00134-004-2422-2$

2. Oeyen SG, Vandijck DM, Benoit DD, Annemans L, Decruyenaere JM. Quality of life after intensive care: A systematic review of the literature. Crit Care Med 2010;38(12):2386-2400. https://doi. care: A systematic review of the
org $/ 10.1097 / \mathrm{ccm} .0 \mathrm{~b} 013 \mathrm{e} 3181 \mathrm{f} 3 \mathrm{dec} 5$

3. Cuthbertson BH, Scott J, Strachan M, Kilonzo M, Vale L. Quality of life before and after intensive care. Anaesthesia 2005;60(4):332-339. https://doi.org/10.1111/j.1365-2044.2004.04109.x

4. Herridge MS, Tansey CM, Matte A, et al. functional disability 5 years after acute respiratory distress syndrome. N Engl J Med 2011;364(14):1293-1304. https://doi.org/10.1056/nejmoa1011802

5. Van der Schaaf M, Beelen A, Dongelmans DA, Vroom MB, Nollet F. Functional status after intensive care: A challenge for rehabilitation professionals to improve outcome. J Rehabil Med 2009;41(5):360366. https://doi.org/10.2340/16501977-0333

6. Sevin CM, Bloom SL, Jackson JC, Wang L, Ely EW, Stollings JL. Comprehensive care of ICU survivors: Development and implementation of an ICU recovery center. J Crit Care 2018;46:141-148. https://doi. org/10.1016/j.jcrc.2018.02.011

7. Needham DM, Sepulveda KA, Dinglas VD, et al. Core outcome measures for clinical research in acute respiratory failure survivors: An international modified Delphi consensus study. Am J Respir Crit Care respiratory failure survivors: An international modified Delphi consensus s
Med 2017;196(9):1122-1130. https://doi.org/10.1164/rccm.201702-0372oc

8. Cuthbertson BH, Roughton S, Jenkinson D, Maclennan G, Vale L. Quality of life in the five years after Cuthbertson BH, Roughton S, Jenkinson D, Maclennan G, Vale L. Quality of life in the
intensive care: A cohort study. Crit Care 2010;14(1):R6. https://doi.org/10.1186/cc8848

9. Nelson JE, Cox CE, Hope AA, Carson SS. Chronic critical illness. Am J Respir Crit Care Med 2010;182(4):446-454. https://doi.org/10.1164/rccm.201002-0210CI

10. MacIntyre NR, Epstein SK, Carson S, Scheinhorn D, Kent C, Muldoon S. Management of patients requiring prolonged mechanical ventilation: Report of a NAMDRC consensus conference. Chest 2005;128(6):3937-3954. https://doi.org/10.1378/chest.128.6.3937

11. Dettmer MR, Damuth E, Zarbiv S, Mitchell JA, Bartock JL, Trzeciak S. Prognostic factors for long-term mortality in critically ill patients treated with prolonged mechanical ventilation: A systematic review. Crit Care Med 2017;45(1):69-74. https://doi.org/10.1097/ccm.0000000000002022
12. Iwashyna TJ, Viglianti EM. Patient and population-level approaches to persistent critical illness and prolonged ICU stays. Crit Care Clin 2018;34(4):493-500. https://doi.org/10.1016/j.ccc.2018.06.001

13. Iwashyna TJ, Hodgson CL, Pilcher D, et al. Timing of onset and burden of persistent critical illness in Australia and New Zealand: A retrospective, population-based, observational study. Lancet Respir Med 2016;4(7):566-573. https://doi.org/10.1016/s2213-2600(16)30098-4

14. Andriolo BN, Andriolo RB, Saconato H, Atallah AN, Valente O. Early versus late tracheostomy for critically ill patients. Cochrane Database Syst Rev 2015, Issue 1. Art. No.: CD007271. https://doi. org/10.1002/14651858.cd007271.pub3

15. Bhagwanjee S, Scribante J. National audit of critical care resources in South Africa: Unit and bed distribution. S Afr Med J 2007;97(12 Pt 3):1311-1314.

16. Bhagwanjee S, Scribante J. National audit of critical care resources: How long before we act? South Afr J Crit Care 2008;24(1):4-6.

17. Van der Merwe E, Kapp J, Pazi S, et al. The SAPS 3 score as a predictor of hospital mortality in a South African tertiary intensive care unit: A prospective cohort study. PLoS ONE 2020;15(5):e0233317. https://doi.org/10.1371/journal.pone.0233317

18. Skinner DL, de Vasconcellos K, Wise R, et al. Critical care admission of South African (SA) surgical patients: Results of the SA Surgical Outcomes Study. S Afr Med J 2017;107(5):411-419. https://doi. org/10.7196/SAMJ.2017.v107i5.11455

19. Gordon K, Allorto N, Wise R. Analysis of referrals and triage patterns in a South African metropolitan adult intensive care service. S Afr Med J 2015;105(6):491-495. https://doi.org/10.7196/ SAMJ.9007

20. Palevsky PM, Liu KD, Brophy PD, et al. KDOQI US Commentary on the 2012 KDIGO Clinical Practice Guideline for Acute Kidney Injury. Am J Kidney Dis 2013;61(5):649-672. https://doi. org/10.1053/j.ajkd.2013.02.349

21. Ferguson ND, Fan E, Camporota L, et al. The Berlin definition of ARDS: An expanded rationale, justification, and supplementary material. Intensive Care Med 2012;38(10):1573-1582. https://doi. org/10.1007/s00134-012-2682-1

22. Shankar-Hari M, Phillips GS, Levy ML, et al. Developing a new definition and assessing new clinical criteria for septic shock: For the Third International Consensus Definitions for Sepsis and Septic Shock (Sepsis-3). JAMA 2016;315(8):775-787. https://doi.org/10.1001/jama.2016.0289

23. RAND Corporation. 36-Item Short Form Survey (SF-36). http://www.rand.org/health/surveys_ tools/mos/mos_core_36item.html (accessed 23 August 2017).

24. Laucis NC, Hays RD, Bhattacharyya T. Scoring the SF-36 in orthopaedics: A brief guide. J Bone Joint Surg Am 2015;97(19):1628-1634. https://doi.org/10.2106/jbjs.o.00030
S

25. Ware JE, Kosinski M, Keller S. SF-36 Physical and Mental Health Summary Scales: A User's Manual. Boston, Mass.: The Health Institute, New England Medical Center, 1994.

26. Maruish ME, Turner-Bowker DM. A Guide to the Development of Certified Modes of Short Form Survey Administration. Lincoln, RI: QualityMetric Incorporated, 2009

27. Herridge MS, Chu LM, Matte A, et al. The Recover Program: Disability risk groups and 1-year outcome after 7 or more days of mechanical ventilation. Am J Respir Crit Care Med 2016;194(7):831844. https://doi.org/10.1164/rccm.201512-2343oc

28. Damuth E, Mitchell JA, Bartock JL, Roberts BW, Trzeciak S. Long-term survival of critically ill patients treated with prolonged mechanical ventilation: A systematic review and meta-analysis. Lancet Respir Med 2015;3(7):544-553. https://doi.org/10.1016/s2213-2600(15)00150-2

29. Engoren M, Arslanian-Engoren C, Fenn-Buderer N. Hospital and long-term outcome after tracheostomy for respiratory failure. Chest 2004;125(1):220-227. https://doi.org/10.1378/ chest.125.1.220

30. Carson SS, Garrett J, Hanson LC, et al. A prognostic model for one-year mortality in patients requiring prolonged mechanical ventilation. Crit Care Med 2008;36(7):2061-2069. https://doi. org/10.1097/ccm.0b013e31817b8925

31. Darvall JN, Boonstra T, Norman J, et al. Persistent critical illness: Baseline characteristics, intensive care course, and cause of death. Crit Care Resusc 2019;21(2):110-118.

32. Mira JC, Brakenridge SC, Moldawer LL, Moore FA. Persistent inflammation, immunosuppression and catabolism syndrome. Crit Care Clin 2017;33(2):245-258. https://doi.org/10.1016/j. ccc.2016.12.001

33. Maglinte GA, Hays RD, Kaplan RM. US general population norms for telephone administration of the SF-36v2. J Clin Epidemiol 2012;65(5):497-502. https://doi.org/10.1016/j.jclinepi.2011.09.008

34. Dowdy DW, Eid MP, Sedrakyan A, et al. Quality of life in adult survivors of critical illness: A systematic review of the literature. Intensive Care Med 2005;31(5):611-620. https://doi.org/10.1007/ s00134-005-2592-6

35. Karachi F, Hanekom S, Faure M. Health-related quality of life of patients 12 months following surgical intensive care discharge. S Afr J Physiother 2011;67(1):28-34. https://doi.org/10.4102/sajp. v67i1.36

36. Niskanen M, Ruokonen E, Takala J, Rissanen P, Kari A. Quality of life after prolonged intensive care, Crit Care Med 1999;27(6):1132-1139. https://doi.org/10.1097/00003246-199906000-00035

37. Oeyen SG, Vandijck DM, Benoit DD, Annemans L, Decruyenaere JM. Quality of life after intensive care: A systematic review of the literature. Crit Care Med 2010;38(12):2386-2400. https://doi. org $/ 10.1097 / \mathrm{ccm} .0 \mathrm{~b} 013 \mathrm{e} 3181 \mathrm{f} 3 \mathrm{dec} 5$

38. Van Aswegen H, Myezwa H, Mudzi W, Becker P. Health-related quality of life of survivors of penetrating trunk trauma in Johannesburg, South Africa. Eur J Trauma Emerg Surg 2011;37(4):419426. https://doi.org/10.1007/s00068-010-0071-4

9. Ridley SA, Wallace PG. Quality of life after intensive care. Anaesthesia 1990;45(10):808-813. https:// doi.org/10.1111/j.1365-2044.1990.tb $14560 . x$

40. Wehler M, Martus P, Geise A, et al. Changes in quality of life after medical intensive care. Intensive Care Med 2001;27(1):154-159. https://doi.org/10.1007/s001340000769

41. Zampieri FG, Bozza FA, Moralez GM, et al. The effects of performance status one week before hospital admission on the outcomes of critically ill patients. Intensive Care Med 2017;43:39-47. https://doi.org/10.1007/s00134-016-4563-5

42. Rivera-Fernandez R, Sanchez-Cruz JJ, Abizanda-Campos R, Vazquez-Mata G. Quality of life before intensive care unit admission and its influence on resource utilization and mortality rate. Crit Care Med 2001;29(9):1701-1709. https://doi.org/10.1097/00003246-200109000-00008

43. Garrouste-Orgeas M, Timsit JF, Montuclard L, et al. Decision-making process, outcome, and 1-year quality of life of octogenarians referred for intensive care unit admission. Intensive Care Med 2006;32(7):1045-1051. https://doi.org/10.1007/s00134-006-0169-7

44. Hofhuis JG, Spronk PE, van Stel HF, Schrijvers AJ, Bakker J. Quality of life before intensive care unit admission is a predictor of survival. Crit Care 2007;11(4):R78. https://doi.org/10.1186/cc5970

45. Badia X, Diaz-Prieto A, Gorriz MT, et al. Using the Euroqol-5D to measure changes in quality of life 12 months after discharge from an intensive care unit. Intensive Care Med 2001;27(12):1901-1907. https://doi.org/10.1007/s00134-001-1137-x

46. Hardcastle TC, Samuels C, Muckart DJ. An assessment of the hospital disease burden and the facilities for the in-hospital care of trauma in KwaZulu-Natal, South Africa. World J Surg 2013;37(7):1550-1561. https://doi.org/10.1007/s00268-012-1889-1 
47. Zaidi AA, Dixon J, Lupez K, et al. The burden of trauma at a district hospital in the Western Cape Province of South Africa. Afr J Emerg Med 2019;9(Suppl):S14-S20. https://doi.org/10.1016/j. afiem.2019.01.007

48. Schneiderman J, van Aswegen H, Becker P. Health related quality of life of survivors of trauma six months after discharge. S Afr J Physiother 2013;69(1):a366. https://doi.org/10.4102/sajp.v69i1.366

49. Norman BC, Jackson JC, Graves JA, et al. Employment outcomes after critical illness: An analysis of the Bringing to Light the Risk Factors and Incidence of Neuropsychological Dysfunction in ICU Survivo cohort. Crit Care Med 2016;44(11):2003-2009. https://doi.org/10.1097/ccm.0000000000001849

50. Griffiths J, Hatch RA, Bishop J, et al. An exploration of social and economic outcome and associated health-related quality of life after critical illness in general intensive care unit survivors: A 12-month follow-up study. Crit Care 2013;17(3):R100. https://doi.org/10.1186/cc12745

51. Needham DM, Dinglas VD, Bienvenu OJ, et al. One year outcomes in patients with acute lung injury randomised to initial trophic or full enteral feeding: Prospective follow-up of EDEN randomised trial. BMJ 2013;346:f1532. https://doi.org/10.1136/bmj.f1532
52. Pletcher H. South Africa: Unemployment rate from 1999 to 2019. Statista, 2020. https://www.statista. com/statistics/370516/unemployment-rate-in-south-africa/ (accessed 1 February 2020).

53. Joynt GM, Gopalan DP, Argent AA, et al. The Critical Care Society of Southern Africa Consensus Statement on ICU Triage and Rationing (Conictri). S Afr Med J 2019;109(8b):613-629. https://doi org/10.7196/SAJCC.2019.v35ilb.383

54. Cox CE, Martinu T, Sathy SJ, et al. Expectations and outcomes of prolonged mechanical ventilation Crit Care Med 2009;37(11):2888-2894; quiz 2904. https://doi.org/10.1097/ccm.0b013e3181ab86ed

Accepted 24 November 2021. 